\title{
ERRATA
}

\section{Impact of early infant feeding practices on mortality in low birth weight infants from rural Ghana}

\section{KM Edmond, BR Kirkwood, CA Tawiah and S Owusu Agyei}

Journal of Perinatology (2009) 29, 181; doi:10.1038/jp.2008.209

Correction to: Journal of Perinatology (2008) 28, 438-444. doi:10.1038/jp.2008.19

Following the publication of the above paper, the author identified the following error in the text:
The fourth coauthor's name was incorrectly cited as 'S0 Agyei'. It should be cited as 'Owusu Agyei $S$ '.

\section{Substance abuse treatment linked with prenatal visits improves perinatal outcomes: a new standard}

\section{NC Goler, MA Armstrong, CJ Taillac and VM Osejo}

Journal of Perinatology (2009) 29, 181; doi:10.1038/p.2008.142

Correction to: Journal of Perinatology (2008) 28, 597-603; doi:10.1038/jp.2008.70

Following the publication of the above paper, the author identified the following error in the text:
SR Kandall is listed as a second author in reference 2 when he should be listed as the second author in reference 3 . 